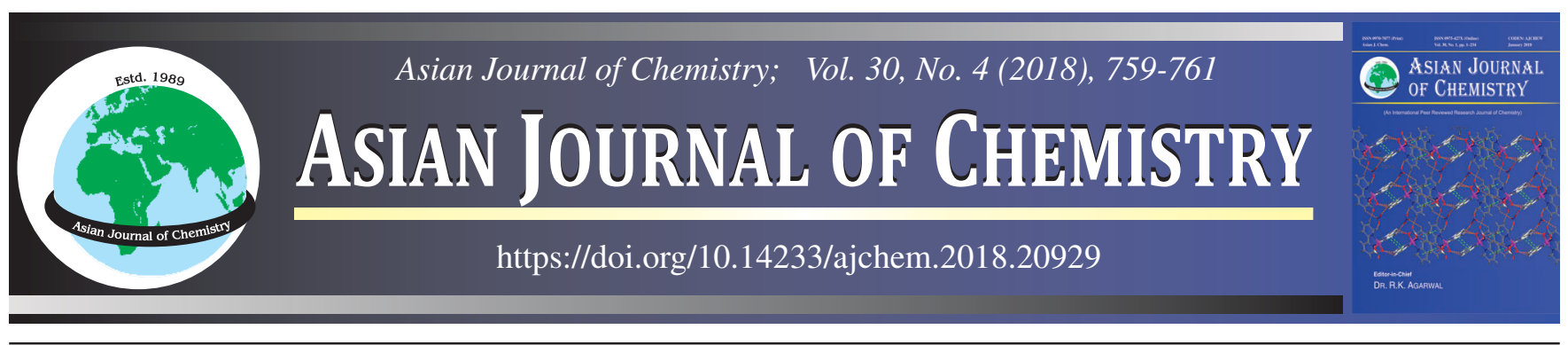

\title{
Effect of Various Extraction Techniques and Solvents on Extract Yield and Sugars Content of Clove (Syzygium aromaticum $\mathbf{L}$.)
}

\author{
Isha Singh, V.K. Madan*, Satya Shree Jangra and Dusyant
}

Medicinal \& Aromatic Plants Section, Old IATTE Building, Chaudhary Charan Singh Haryana Agricultural University, Hisar-125 004, India

*Corresponding author: E-mail: vikku60@gmail.com

Received: 18 July 2017; Accepted: 29 September 2017;

Published online: 28 February 2018;

AJC-18778

For the standardization of herbal products, selection of a suitable extraction technique is important. This study was conducted to observe the effect of various extraction techniques viz. maceration followed by mechanical shaking, refluxing, Soxhlet extraction and centrifugation and solvents viz. acetone, ethanol and water on extract yield and sugars content of clove buds. In clove buds, highest extract yield (27.64 $\mathrm{g} / 100 \mathrm{~g})$, total sugars $(28.91 \mathrm{mg} / \mathrm{g})$, reducing sugars $(28.50 \mathrm{mg} / \mathrm{g})$ and non-reducing sugars $(0.41 \mathrm{mg} / \mathrm{g})$ contents were found in extracts obtained by Soxhlet technique followed by refluxing, mechanical shaking/centrifugation. Amongst solvents, extract yield (34.29 g/100 $\mathrm{g})$, total sugars $(29.58 \mathrm{mg} / \mathrm{g})$, reducing sugars $(29.18 \mathrm{mg} / \mathrm{g})$ and non-reducing sugars $(0.40 \mathrm{mg} / \mathrm{g})$ were highest in water extracts followed by ethanol and acetone extracts. Thus, the extract yield and sugars content of clove are dependent on the kind of extraction technique used and solvent polarity.

Keywords: Syzygium aromaticum, Extraction techniques, Extract yield, Sugars.

\section{INTRODUCTION}

Clove (Syzygium aromaticum L.) belongs to family Myrtaceae. They are aromatic dried buds of an evergreen tree and cultivated in Madagascar, Sri Lanka, Indonesia, Philippines, India, Tanzania and South of China. Clove buds are deep brown in colour and best used as complete buds. Clove buds have a warm, spicy, peppery, sweet, pungent, aromatic and musty aroma. The flavour is very sweetly pungent, fruity, strongly aromatic and astringent and leaves a numbing sensation in the mouth. Major constituents of dried clove buds are total sugars $(2.36 \%)$, proteins (5\%), mineral matter $(5.2 \%)$, steam-volatile oil (15$20 \%$ ) and carbohydrates (61\%) [1]. Clove buds also possess various vitamins such as vitamin $\mathrm{A}, \mathrm{B}_{1}, \mathrm{~B}_{2}, \mathrm{~B}_{3}$ and ascorbic acid [2]. Leaves, stem, buds and fruits of clove tree are rich in volatile oil. The major component of clove oil is a phenol, namely eugenol. Clove bud oil contains eugenol, eugenyl acetate and $\beta$-caryophyllene, which make up to $99 \%$ of the oil [3]. Fruity aroma of clove oil is due to the presence of methyl- $n$ amyl ketone. Non-volatile constituents of clove include flavonoids, sterols, tannins and triterpenes. A variety of flavonoids, including kaempferol, rhamnetin, quercetin and myricetin are present in clove buds. Sterols found in clove include sitosterol, stigmasterol and campesterol [3]. Antioxidant activity of eugenol is comparable to that of synthetic antioxidants [4]. Clove has highest capacity to reduce lipid peroxidation. Clove acts as an iron chelator by inhibiting hydroxyl free radicals [5]. Clove also shows pharmacological activities like antimicrobial, antiviral, chemopreventive, hepatoprotective, antidiabetic, antiinflammatory, antistress, antipyretic, insecticidal activities, anesthetic effects and mosquito repellant [3]. They are widely used as medicines as carminative and stimulant.

Several factors such as oxidizing agent, $\mathrm{pH}$ and temperature can affect the quality of the extract produced by an extraction process [6]. It is important to select an appropriate extraction technique for standardization of herbal products because it is necessary to extract desirable constituents, leaving out unrequited constituents with the help of solvent. A good extraction technique is expected to be less time consuming and offers high yield of active compounds without sacrificing their functionality. Extraction efficiency is commonly a function of process conditions. Literature survey revealed that no systematic work has been done on the comparative analysis of various extraction techniques and solvents on extract yield and sugars content of clove buds. Thus, the objective of this study was to find out the effect of various extraction techniques and solvents on extract yield and sugars content of clove buds.

\section{EXPERIMENTAL}

Germplasm material of dried clove buds was used for this study. A fine powder of healthy clove buds was prepared using 
warring blender. Samples of powdered clove buds were extracted with solvents viz. acetone, ethanol and water by using following extraction techniques: (1) Maceration followed by mechanical shaking; (2) Refluxing; (3) Soxhlet extraction; (4) Centrifugation.

The detailed extraction method is described in previously published paper [7]. All extractions were performed in triplicate. Extracts were used for the estimation of extract yield and sugars content.

Chemicals: Highest purity chemicals were deployed for various estimations.

Estimation of extract yield: The extract yield was calculated by gravimetric method. Each extract was dried up completely in a beaker and extract yield was calculated by the difference in weight of beaker before and after drying. Extract yield was expressed as gram per hundred gram $(\mathrm{g} / 100 \mathrm{~g})$.

Estimation of total sugars content: Total sugars content was determined by phenol sulphuric acid method [8] using glucose as standard. Detailed method is discussed in previously published paper [9]. The total sugars content present in various extracts was calculated and results were expressed as milligrams per gram $(\mathrm{mg} / \mathrm{g})$.

Estimation of reducing sugars content: Reducing sugars content was determined by Nelson-Somogyi method [10] using glucose as standard. The detailed method is discussed in published article [9]. The reducing sugars content present in various extracts was calculated and results were expressed as milligrams per gram $(\mathrm{mg} / \mathrm{g})$.

Estimation of non-reducing sugars content: Non-reducing sugars content was calculated as the difference of total sugars content and reducing sugars content.

Non-reducing sugars content $=$

Total sugars content - Reducing sugars content

\section{RESULTS AND DISCUSSION}

Extract yield: Amongst extraction techniques, extract yield $(\mathrm{g} / 100 \mathrm{~g})$ of clove buds extracts obtained by Soxhlet technique was highest i.e. 27.64 followed by refluxing (21.70), centrifugation (13.94) and mechanical shaking (12.22). Amongst solvents, water extracts of clove buds showed highest (34.29) extract yield followed by ethanol (13.07) and acetone (9.28) extracts (Table-1). Exhaustive extraction ability of Soxhlet extraction technique is responsible for higher extract yield. Present findings are in agreement with previous investigations on seven medicinal plants showing that higher extract yields were obtained by refluxing (4.86-42.4 g/100 g) technique in comparison to shaking (2.23-34.5 g/100 g) which is due to the reason that hot solvents used in refluxing are more effective for the extraction of antioxidative constituents thus are responsible for higher extract yields [11]. Extract yield of Bauhinia purpurea was higher in extracts obtained by Soxhlet technique (13.5 g/100 g) in comparison to maceration $(8.3 \mathrm{~g} /$ $100 \mathrm{~g}$ ) due to its exhaustive extraction ability [12]. The extract yield from Quercus infectoria galls. was highest in water extract $(80.03 \%)$ followed by ethanol $(45.77 \%)$ and acetone $(43.57 \%)$ extracts showing that polar compounds in plants are easier to extract with more polar solvents [13].

Total sugars, reducing sugars, non-reducing sugars: Contents of total sugars, reducing sugars and non-reducing sugars $(\mathrm{mg} / \mathrm{g})$ in various extracts of clove buds varied widely. Amongst extraction techniques the contents of total sugars, reducing sugars and non-reducing sugars (Tables 2-4) were highest (28.91, 28.50 and $0.41 \mathrm{mg} / \mathrm{g}$, respectively) in extracts obtained by Soxhlet technique followed by refluxing (25.94, 25.64 and 0.30 , respectively), centrifugation $(19.27,19.06$ and 0.21 , respectively) and mechanical shaking $(19.06,18.86$ and

TABLE-1

EXTRACT YIELD (g/100 g) OF CLOVE BUDS EXTRACTS OBTAINED BY DIFFERENT EXTRACTION TECHNIQUES

\begin{tabular}{|c|c|c|c|c|c|c|}
\hline \multirow{3}{*}{ Spices } & \multirow{3}{*}{ Extraction technique } & \multicolumn{5}{|c|}{ Extract yield $(\mathrm{g} / 100 \mathrm{~g})$} \\
\hline & & \multicolumn{5}{|c|}{ Solvent } \\
\hline & & Acetone & Ethanol & Water & Mean & Increase over $\mathrm{T}_{1}(\%)$ \\
\hline \multirow{5}{*}{ Clove buds } & Mechanical shaking & $4.55 \pm 0.08$ & $5.17 \pm 0.06$ & $26.95 \pm 0.12$ & 12.22 & - \\
\hline & Refluxing & $12.02 \pm 0.06$ & $18.65 \pm 0.05$ & $34.44 \pm 0.04$ & 21.70 & 77.6 \\
\hline & Soxhlet & $13.65 \pm 0.04$ & $20.90 \pm 0.08$ & $48.37 \pm 0.12$ & 27.64 & 126.2 \\
\hline & Centrifugation & $6.89 \pm 0.04$ & $7.54 \pm 0.06$ & $27.38 \pm 0.13$ & 13.94 & 14.1 \\
\hline & Mean & 9.28 & 13.07 & 34.29 & & \\
\hline SE (mean) & \multicolumn{6}{|c|}{ Extraction technique $=0.04 ;$ Solvent $=0.04 ;$ Extraction technique $\times$ Solvent $=0.08$} \\
\hline $\mathrm{CD}$ at $5 \%$ & \multicolumn{6}{|c|}{ Extraction technique $=0.13 ;$ Solvent $=0.11 ;$ Extraction technique $\times$ Solvent $=0.22$} \\
\hline $\mathrm{CV}(\%)$ & \multicolumn{6}{|c|}{0.69} \\
\hline
\end{tabular}

TABLE-2

TOTAL SUGARS (mg/g) IN CLOVE BUDS EXTRACTS OBTAINED BY DIFFERENT EXTRACTION TECHNIQUES

\begin{tabular}{|c|c|c|c|c|c|c|}
\hline \multirow{3}{*}{ Spices } & \multirow{3}{*}{ Extraction technique } & \multicolumn{5}{|c|}{ Total sugars $(\mathrm{mg} / \mathrm{g})$} \\
\hline & & \multicolumn{5}{|c|}{ Solvent } \\
\hline & & Acetone & Ethanol & Water & Mean & Increase over $\mathrm{T}_{1}(\%)$ \\
\hline \multirow{5}{*}{ Clove buds } & Mechanical shaking & $12.46 \pm 0.31$ & $19.64 \pm 0.51$ & $25.10 \pm 0.36$ & 19.06 & - \\
\hline & Refluxing & $19.15 \pm 0.19$ & $26.31 \pm 0.23$ & $32.35 \pm 0.19$ & 25.94 & 36.1 \\
\hline & Soxhlet & $22.21 \pm 0.10$ & $29.06 \pm 0.30$ & $35.47 \pm 0.12$ & 28.91 & 51.7 \\
\hline & Centrifugation & $13.12 \pm 0.20$ & $19.29 \pm 0.27$ & $25.39 \pm 0.18$ & 19.27 & 1.1 \\
\hline & Mean & 16.74 & 23.58 & 29.58 & & \\
\hline SE (mean) & \multicolumn{6}{|c|}{ Extraction technique $=0.16 ;$ Solvent $=0.13 ;$ Extraction technique $\times$ Solvent $=0.27$} \\
\hline $\mathrm{CD}$ at $5 \%$ & \multirow{2}{*}{\multicolumn{6}{|c|}{ Extraction technique $=0.46 ;$ Solvent $=0.40 ;$ Extraction technique $\times$ Solvent $=$ NA }} \\
\hline $\mathrm{CV}(\%)$ & & & & & & 2.00 \\
\hline
\end{tabular}




\begin{tabular}{|c|c|c|c|c|c|c|}
\hline \multicolumn{7}{|c|}{$\begin{array}{r}\text { TABLE-3 } \\
\text { REDUCING SUGARS (mg/g) IN CLOVE BUDS EXTRACTS OBT }\end{array}$} \\
\hline \multirow{3}{*}{ Spices } & \multirow{3}{*}{ Extraction technique } & \multicolumn{5}{|c|}{ Reducing sugars $(\mathrm{mg} / \mathrm{g}$ ) } \\
\hline & & \multicolumn{5}{|c|}{ Solvent } \\
\hline & & Acetone & Ethanol & Water & Mean & Increase over $\mathrm{T}_{1}(\%)$ \\
\hline \multirow{5}{*}{ Clove buds } & Mechanical shaking & $12.31 \pm 0.27$ & $19.44 \pm 0.53$ & $24.84 \pm 0.35$ & 18.86 & - \\
\hline & Refluxing & $18.98 \pm 0.19$ & $26.01 \pm 0.23$ & $31.94 \pm 0.22$ & 25.64 & 36.0 \\
\hline & Soxhlet & $21.98 \pm 0.12$ & $28.71 \pm 0.30$ & $34.81 \pm 0.05$ & 28.50 & 51.1 \\
\hline & Centrifugation & $12.96 \pm 0.20$ & $19.08 \pm 0.28$ & $25.13 \pm 0.16$ & 19.06 & 1.1 \\
\hline & Mean & 16.56 & 23.31 & 29.18 & & \\
\hline SE (mean) & \multicolumn{6}{|c|}{ Extraction technique $=0.16 ;$ Solvent $=0.14 ;$ Extraction technique $\times$ Solvent $=0.27$} \\
\hline $\mathrm{CD}$ at $5 \%$ & \multicolumn{6}{|c|}{ Extraction technique $=0.46 ;$ Solvent $=0.40 ;$ Extraction technique $\times$ Solvent $=\mathrm{NA}$} \\
\hline $\mathrm{CV}(\%)$ & \multicolumn{6}{|c|}{ 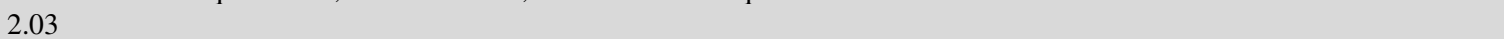 } \\
\hline
\end{tabular}

TABLE-4

NON-REDUCING SUGARS (mg/g) IN CLOVE BUDS EXTRACTS OBTAINED BY DIFFERENT EXTRACTION TECHNIQUES

\begin{tabular}{|c|c|c|c|c|c|c|}
\hline \multirow{3}{*}{ Spices } & \multirow{3}{*}{ Extraction technique } & \multicolumn{5}{|c|}{ Non-reducing sugars $(\mathrm{mg} / \mathrm{g})$} \\
\hline & & \multicolumn{5}{|c|}{ Solvent } \\
\hline & & Acetone & Ethanol & Water & Mean & Increase over $\mathrm{T}_{1}(\%)$ \\
\hline \multirow{5}{*}{ Clove buds } & Mechanical shaking & $0.15 \pm 0.04$ & $0.20 \pm 0.02$ & $0.26 \pm 0.02$ & 0.20 & - \\
\hline & Refluxing & $0.19 \pm 0.01$ & $0.30 \pm 0.02$ & $0.42 \pm 0.04$ & 0.30 & 50.0 \\
\hline & Soxhlet & $0.23 \pm 0.02$ & $0.35 \pm 0.02$ & $0.66 \pm 0.03$ & 0.41 & 105.0 \\
\hline & Centrifugation & $0.16 \pm 0.03$ & $0.21 \pm 0.02$ & $0.26 \pm 0.02$ & 0.21 & 5.0 \\
\hline & Mean & 0.18 & 0.27 & 0.40 & & \\
\hline SE (mean) & \multicolumn{6}{|c|}{ Extraction technique $=0.02 ;$ Solvent $=0.01 ;$ Extraction technique $\times$ Solvent $=0.03$} \\
\hline $\mathrm{CD}$ at $5 \%$ & \multicolumn{6}{|c|}{ Extraction technique $=0.46 ;$ Solvent $=0.04 ;$ Extraction technique $\times$ Solvent $=0.08$} \\
\hline
\end{tabular}

0.20, respectively). Amongst solvents, contents of total sugars, reducing sugars and non-reducing sugars were highest $(29.58$, 29.18 and $0.40 \mathrm{mg} / \mathrm{g}$, respectively) in water extracts followed by ethanol $(23.58,23.31$ and 0.27 , respectively) and acetone (16.74, 16.56 and 0.18, respectively) extracts (Tables 2-4). Sugar molecules have many polar hydroxyl (-OH) groups and are highly polar in nature. Sugars are able to form hydrogen bonds with water or ethanol molecules [14]. Solubility of Dglucose is higher in water $(5.271 \mathrm{M})$ than ethanol $(0.011 \mathrm{M})$. Sucrose molecule has three hydrophilic oxygen atoms, 8 hydroxyl groups and 14 hydrogen atoms. Thus sucrose easily forms hydrogen bonds with water enabling easy dissolution of sucrose in water. Solubility of sucrose is significantly lower in organic solvents in comparison to water [56]. Present results are in agreement with the previous studies that clove contained $2.36 \%$ total sugars in it [3].

\section{Conclusion}

Present study revealed that extract yield and sugars content of clove buds were affected by the type of extraction technique used and solvent polarity. Highest extract yield and sugars content were found in water extracts obtained from Soxhlet extraction technique.

\section{REFERENCES}

1. USDA, National Nutrient Database for Standard Reference, Release 18 (2005).

2. R.D. Tainter and T.A. Grenis, Spices and Seasonings Food Science and Technology, VCH Publishers: New York, pp. 226 (1993).
3. M. Parle and D. Khanna, Int. Res. J. Pharm., 2, 47 (2011).

4. H.J.D. Dorman and S.G. Deans, J. Appl. Microbiol., 88, 308 (2000); https://doi.org/10.1046/j.1365-2672.2000.00969.x.

5. I. Gulcin, I.G. Sat, S. Beydemir, M. Elmastas and O.I. Kufrevioglu, Food Chem., 87, 393 (2004);

https://doi.org/10.1016/j.foodchem.2003.12.008.

6. R. Tsao and Z. Deng, J. Chromatogr. B Analyt. Technol. Biomed. Life Sci., 812, 85 (2004);

https://doi.org/10.1016/S1570-0232(04)00764-0.

7. I. Singh, V.K. Madan, S.S. Jangra and S. Singh, Asian J. Chem., 28, 801 (2016); https://doi.org/10.14233/ajchem.2016.19522.

8. M. DuBois, K.A. Gilles, J.K. Hamilton, P.A. Rebers and F. Smith, Anal. Chem., 28, 350 (1956);

https://doi.org/10.1021/ac60111a017.

9. S. Gulati, V.K. Madan, S. Singh, I. Singh and Dusyant, Asian J. Chem., 29, 1683 (2017); https://doi.org/10.14233/ajchem.2017.20536.

10. M. Somogyi, J. Biol. Chem., 195, 19 (1952).

11. B. Sultana, F. Anwar and M. Ashraf, Molecules, 14, 2167 (2009); https://doi.org/10.3390/molecules 14062167.

12. H.V. Annegowda, M.N. Mordi, S. Ramanathan, M.R. Hamdan and S.M. Mansor, Food Anal. Methods, 5, 226 (2012); https://doi.org/10.1007/s12161-011-9228-y.

13. M.N. Hasmida, A.R. Nur Syukriah, M.S. Liza and C.Y. Mohd Azizi, Int. Food Res. J., 21, 1075 (2014).

14. E.A. Macedo, Pure Appl. Chem., 77, 559 (2005); https://doi.org/10.1351/pac200577030559.

15. Z. Bubnik and P. Kadlec, eds.: M. Mathlouthi and P. Reiser, Sucrose: Properties and Applications, In: Sucrose Solubility, Blackie Academic \& Professional: An Imprint of Chapman \& Hall, UK, pp. 101-125 (1995). 